\title{
Pancytopenia associated with clonazepam
}

\author{
Marnelli A Bautista-Quach', Yu-Min Liao², Chung-Tsen Hsueh ${ }^{3^{*}}$
}

\begin{abstract}
We report a case of a 48-year-old Chinese female with end-stage renal disease and chronic anemia on hemodialysis. Clonazepam was prescribed for myoclonus disorder two weeks prior to her hospitalization. Subsequently, she was hospitalized for neutropenic fever with thrombocytopenia and worsening anemia. Bone marrow examination demonstrated a markedly hypocellular marrow (10-20\% total cellularity). Clonazepam was discontinued, with gradual improvement of thrombocytopenia, and neutropenia in 1-2 weeks. To our knowledge, this is the first reported case of pancytopenia associated with clonazepam. We recommend patients taking clonazepam to be monitored with regular complete blood count to check for clinically significant pancytopenia or thrombocytopenia.
\end{abstract}

\section{Introduction}

Clonazepam, a benzodiazepine derivative is used for the treatment of epilepsy, psychiatric, and neurologic disorders [1]. Clonazepam has also been utilized in alleviating movement disorders and restless leg syndrome in patients with end-stage renal disease $[2,3]$. Cases of thrombocytopenia from clonazepam and other benzodiazepines have been described [4-6]. We report an event of pancytopenia associated with clonazepam in a patient with end-stage renal disease.

\section{Case Report}

A 48-year-old Chinese female with end-stage renal disease on hemodialysis, and mild chronic anemia presented with fever, chills and new-onset leukopenia and thrombocytopenia. She was started on clonazepam (0.25 mg orally twice a day) for myoclonus approximately two weeks prior. Her other medicines included erythropoietin, felodipine, aluminum hydroxide, calcium carbonate, labetalol, folic acid, and daily vitamin B complex. She received two units of packed red blood cells for worsening anemia, with a hemoglobin value of $6 \mathrm{~g} / \mathrm{dL}$. Post-transfusion complete blood count $(\mathrm{CBC})$ revealed a hemoglobin of $7.6 \mathrm{~g} / \mathrm{dL}$ (MCV $92 \mathrm{fL}$ ), white blood cell (WBC) count of $460 / \mu \mathrm{L}$ (absolute neutrophil count of $69 / \mu \mathrm{L}$ ), and platelet count of $89,640 / \mu \mathrm{L}$. She subsequently developed fever and chills and was admitted to the hospital the following day.

\footnotetext{
* Correspondence: chsueh@llu.edu

${ }^{3}$ Division of Medical Oncology and Hematology, Loma Linda University Medical Center, Loma Linda, CA 92354, USA
}

On the day of admission, $\mathrm{CBC}$ showed a WBC count of $386 / \mu \mathrm{L}$ (absolute neutrophil count of $49 / \mu \mathrm{L}$ ), hemoglobin of $8.17 \mathrm{~g} / \mathrm{dL}$ (MCV $91.2 \mathrm{fL}$ ), and platelet count of $62,300 / \mu \mathrm{L}$. Blood culture was obtained which exhibited no growth of microorganisms. She was empirically treated with broad-spectrum antibiotics. Evaluation for human immunodeficiency virus, hepatitis B and hepatitis $C$ viruses were negative. Antinuclear antibody study was non-reactive. Both folate and vitamin B12 levels were within normal ranges. Peripheral blood smear revealed pancytopenia without leukemic blasts. A bone marrow biopsy predominately consisted of adipose tissue, with significantly decreased myeloid and erythroid precursors, as well as megakaryocytes, reflecting a $10-20 \%$ overall cellularity (Figs. 1 and 2). No aggregates of blasts or atypical cells were identified. Review of medications suggested that clonazepam, which was added to the patient's regimen two weeks prior to admission, most likely precipitated pancytopenia. Clonazepam was consequently discontinued. Her other medications were maintained. The thrombocytopenia resolved in four days, and neutropenia gradually improved within 1-2 weeks. She was discharged about a week from the day of admission, with $\mathrm{CBC}$ showing WBC count of $1,460 / \mu \mathrm{L}$, hemoglobin of $7.56 \mathrm{~g} / \mathrm{dL}$, and platelet count of $246,000 / \mu \mathrm{L}$.

\section{Discussion}

Several hypotheses have been illustrated in drug-induced aplastic anemia including direct toxic effect to hematopoietic elements, and immune-mediated destruction secondary to idiosyncratic reaction to a drug [7]. El-Sayed and Symonds reported a case of mild pancytopenia in a
C Biomed Central

() 2010 Bautista-Quach et al; licensee BioMed Central Ltd. This is an Open Access article distributed under the terms of the Creative Commons Attribution License (http://creativecommons.org/licenses/by/2.0), which permits unrestricted use, distribution, and reproduction in any medium, provided the original work is properly cited. 


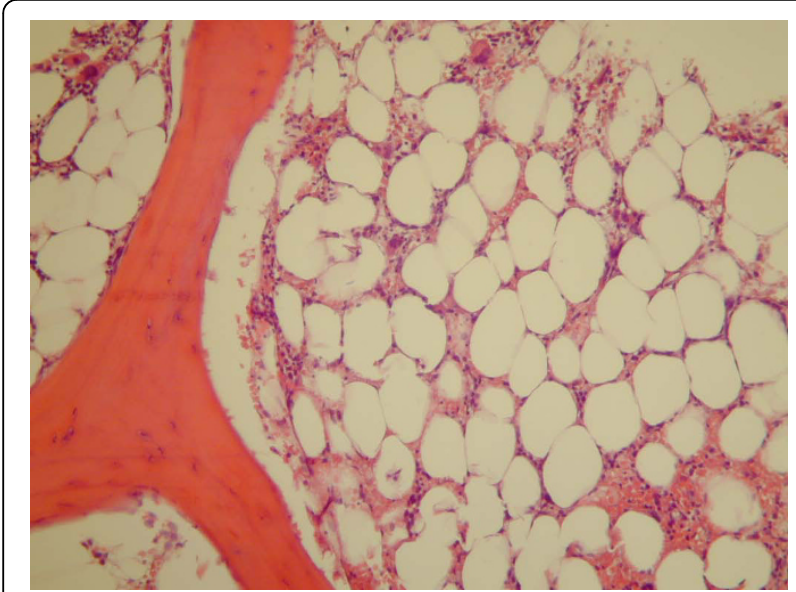

Figure 1 Bone marrow biopsy (hematoxylin and eosin, 200x) Trephine core biopsy showed predominant adipose tissue with significantly decreased hematopoietic elements (10-20\% total marrow cellularity).

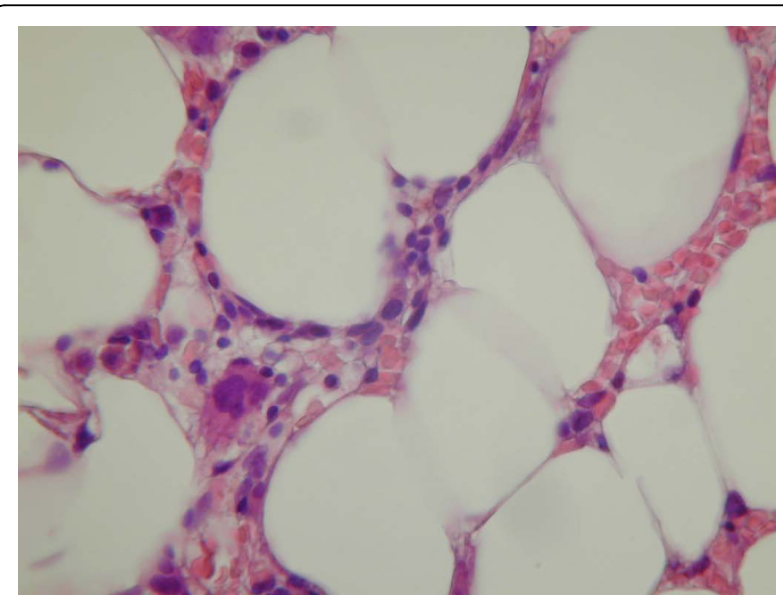

Figure 2 Bone marrow biopsy (hematoxylin and eosin, 400x) Trephine core biopsy showed occasional scattered erythroid and myeloid precursors, and a megakaryocyte.

patient receiving lorazepam and pelvic radiotherapy with a nadir WBC of $2,300 / \mu \mathrm{L}$, hemoglobin of $11.2 \mathrm{~g} / \mathrm{dL}$, and platelet of $90,000 / \mu \mathrm{L}$ [8]. However, bone marrow evaluation was not performed to exclude primary or radiationrelated hematologic conditions. Hence, direct effect from radiotherapy could not be completely excluded. Additionally, benzodiazepine-induced thrombocytopenia has been shown to be mediated by platelet-specific antibodies [6].

To our knowledge, our case represents the first reported occurrence of pancytopenia associated with clonazepam. Patients taking clonazepam must be monitored with regular CBC analyses to check for likely development of clinically significant pancytopenia or thrombocytopenia. If indicated, serology may also be pursued to determine the presence of benzodiazepinedependent antibodies against platelet. Cessation of the drug usually results in gradual improvement of blood counts. Patients should not be re-challenged once hematologic dyscrasia has been documented.

\section{Consent}

Written informed consent was obtained from the patient for publication of this case report and accompanying images. A copy of the written consent is available for review by the Editor-in-Chief of this journal.

\section{Competing interests}

The authors declare that they have no competing interests.

\section{Authors' contributions}

$M B Q$, YML and $C T H$ performed literature review, and participated in the composition of this case report. YML and $\mathrm{CH}$ obtained patient's consent, pertinent clinical data, and photomicrographs. All authors read and approved the final manuscript.

\section{Author details}

'Department of Pathology and Laboratory Medicine, Loma Linda University Medical Center, Loma Linda, CA 92354, USA. ${ }^{2}$ Department of Internal Medicine, China Medical University Hospital, Taichung, Taiwan, China. ${ }^{3}$ Division of Medical Oncology and Hematology, Loma Linda University Medical Center, Loma Linda, CA 92354, USA.

Received: 28 May 2010 Accepted: 14 July 2010 Published: 14 July 2010

\section{References}

1. Morishita S: Clonazepam as a therapeutic adjunct to improve the management of depression: a brief review. Hum Psychopharmacol 2009, 24(3):191-198.

2. Mandel S, Au S, Rudnick M: Clonazepam in Dialysis Encephalopathy. JAMA 1982, 247(13):1810-b-1811.

3. Brouns R, De Deyn PP: Neurological complications in renal failure: a review. Clin Neurol Neurosurg 2004, 107(1):1-16.

4. Veall RM, Hogarth HC: Letter: Thrombocytopenia during treatment with clonazepam. Br Med J 1975, 4(5994):462.

5. Livingston S, Pauli LL: Benzodiazepine anticonvulsant. Arch Neurol 1976, 33(10):731.

6. Conti L, Gandolfo GM: Benzodiazepine-induced thrombocytopenia. Demonstration of drug-dependent platelet antibodies in two cases. Acta Haematol 1983, 70(6):386-388.

7. Young NS: Acquired aplastic anemia. Ann Intern Med 2002, 136(7):534-546.

8. El-Sayed S, Symonds RP: Lorazepam induced pancytopenia. Br Med J (Clin Res Ed) 1988, 296(6632):1332.

doi:10.1186/1756-8722-3-24

Cite this article as: Bautista-Quach et al:: Pancytopenia associated with clonazepam. Journal of Hematology \& Oncology 2010 3:24.

\section{Submit your next manuscript to BioMed Central and take full advantage of:}

- Convenient online submission

- Thorough peer review

- No space constraints or color figure charges

- Immediate publication on acceptance

- Inclusion in PubMed, CAS, Scopus and Google Scholar

- Research which is freely available for redistribution 